\title{
Predicting Concrete Compressive Strength and Modulus of Rupture Using Different NDT Techniques
}

\author{
Wilfrido Martínez-Molina, ${ }^{1,2}$ Andrés Antonio Torres-Acosta, ${ }^{2,3}$ \\ Juan Carlos Jáuregui, ${ }^{2}$ Hugo Luis Chávez-García, ${ }^{1}$ Elia Mercedes Alonso-Guzmán, ${ }^{1}$ \\ Mario Graff, ${ }^{4}$ and Juan Carlos Arteaga-Arcos ${ }^{5}$ \\ ${ }^{1}$ Facultad de Ingeniería Civil, Laboratorio de Materiales, Ciudad Universitaria, Universidad Michoacana de San Nicolás de Hidalgo, \\ Avenida Francisco J. Múgica s/n, Colonia Felicitas del Río, 58040 Morelia, MICH, Mexico \\ ${ }^{2}$ Facultad de Ingeniería, Ciudad Universitaria, Universidad Autónoma de Querétaro, Cerro de las Campanas s/n, \\ 76010 Santiago de Querétaro, QRO, Mexico \\ ${ }^{3}$ Instituto Mexicano del Transporte, 76703 Sanfandila, QRO, Mexico \\ ${ }^{4}$ INFOTEC, Centro de Investigación e Innovación en Tecnologías de la Información y Comunicación, Cátedras-CONACyT, \\ Circuito Tecnopolo Sur, No. 112 Colonia Fracc. Tecnopolo Pocitos, 20313 Aguascalientes, AGS, Mexico \\ ${ }^{5}$ Facultad de Ciencias, Universidad Autónoma del Estado de México, Campus Universitario "El Cerrillo", \\ El Cerrillo Piedras Blancas, 50200 Toluca, MEX, Mexico
}

Correspondence should be addressed to Wilfrido Martínez-Molina; wilfridomartinezmolina@gmail.com

Received 13 May 2014; Accepted 6 November 2014; Published 4 December 2014

Academic Editor: Jun Liu

Copyright (C) 2014 Wilfrido Martínez-Molina et al. This is an open access article distributed under the Creative Commons Attribution License, which permits unrestricted use, distribution, and reproduction in any medium, provided the original work is properly cited.

Quality tests applied to hydraulic concrete such as compressive, tension, and bending strength are used to guarantee proper characteristics of materials. All these assessments are performed by destructive tests (DTs). The trend is to carry out quality analysis using nondestructive tests (NDTs) as has been widely used for decades. This paper proposes a framework for predicting concrete compressive strength and modulus of rupture by combining data from four NDTs: electrical resistivity, ultrasonic pulse velocity, resonant frequency, and hammer test rebound with DTs data. The model, determined from the multiple linear regression technique, produces accurate indicators predictions and categorizes the importance of each NDT estimate. However, the model is identified from all the possible linear combinations of the available NDT, and it was selected using a cross-validation technique. Furthermore, the generality of the model was assessed by comparing results from additional specimens fabricated afterwards.

\section{Introduction}

In the building industry, the measurement of certain physical and mechanical properties of concrete is particularly important, such as compressive strength $\left(f^{\prime} c\right)$ and modulus of rupture (MOR). Test methods to obtain $f^{\prime} c$ consist of applying a compressive axial load to molded cylinders or cores. The $f^{\prime} c$ of the specimen is calculated by dividing the maximum load reached during the test by the cross-sectional area of the specimen [1]; the method to determine MOR includes the determination of the flexural strength of concrete from simply supported unreinforced concrete beams, where a central load is applied to the beam until fracture (also called a three-point load test: the load applied at the center of the beam and the other two are the supports). The result of such test is reported as the MOR, and might be used to determine compliance with the materials' specifications or as a basis for proportioning, mixing, and placement operations for slabs and pavements [2]. Traditionally, these estimates have been obtained following destructive methods, which are the standard ones to determine the mechanical resistance (i.e., compressive, tension, and bending strength) [3]. However, these tests are often costly and time consuming. For example, to determine the compressive strength of concrete, it is necessary to process a large amount of testing samples (at least fifteen) [4]; then a compressometer is required in order 
to determine the elastic modulus; these samples are deformed and destroyed in order to determine the compressive strength and the static modulus of elasticity [5]. As it can be seen, this procedure modifies the samples, and, consequently, it is impossible to repeat the test in the same sample, in case it would be necessary [6].

On the other hand, it is not easy to determine the mechanical characteristics of the materials using only NDT procedures. This problem is more evident since the models are obtained with laboratory settings and under strict controlled conditions. As a consequence, it is necessary to evaluate the applicability of these models in uncontrolled environments and using different conditions from those used in the formulation of an empirical mechanistic model [7].

One particular characteristic of most of these NDTs is that they can be conducted at the work place and can be used to determine certain properties of already built structures; this process is known as in-place testing [8].

In accordance with ACI 228-1R-03, the objective of inplace testing is to estimate the compressive strength of concrete by the use of NDTs. In order to validate the results, it is necessary to have a known relationship between these results and the mechanical resistance obtained by DTs. This relationship is usually established by performing DTs of drilled cores taken from adjacent locations where the in-place test is conducted. The accuracy of the estimated compressive strength depends on the correlation between the strength of the concrete and the quantity measured by the in-place test. As a general index of concrete strength, the compressive strength of concrete $f^{\prime} c$ is important in the performance assessment of existing reinforced concrete structures [9]. On the other hand, the MOR is very useful, especially in relation to road slab design and airfield runways, because the flexure tension is a critical factor to determine concrete's performance in such applications [10].

When NDT first appeared for concrete application, it was common to model the prediction of the concrete strength using only one of the above tests. However, as found by many researchers, the combination of different NDTs can lead to more accurate and reliable models [9, 11-13]. In order to approximate the appropriate estimates of indicators (response variables), for example, Ploix et al. [14] performed a combination or fusion of NDT data as radar test, electrical resistivity and capacity, infrared thermography, impact echo, and ultrasound to predict the simultaneous estimation of the water saturation and porosity rate in concrete for undamaged concretes measured in laboratory conditions. They measured different NDT parameters, such as frequencies, velocities, and attenuations, and after that they conducted an statistical analysis with the purpose of identifying empirical correlations, linking each experimental parameter to both searched indicators. There were identified correlations with bilinear regressions, as a first approximation, but since some different NDT measurements are very sensitive to material heterogeneity, variability, and experimental noise, relative disagreement or conflict between sources of information happened (i.e., measurements); thus the prediction models rapidly became ill-conditioned. Therefore, it was decided to combine several NDT techniques (at least three) providing more suitable information. Kaftandjian et al. [15] used a data fusion approach to improve weld inspection by NDT, combining the use of evidence theory and fuzzy logic, in their framework. X-ray and ultrasonic inspection were modeled in order to generate $3 \mathrm{D}$ images from both NDTs for evaluating defect detection and defect sizing of welded joints for industrial purposes, showing that the fusion of data significantly enhances the reliability of the defect recognition. Maierhofer et al. [16] used radar, ultrasonic, impact echo, and thermography data fusion for predicting deterioration of concrete vehicular bridges, noting that the data fusion technique increases reliability, and improved the accuracy of the quantitative results, exploiting the different, and sometimes complementary, physical effects provided for different NDTs. Shah and Ribakov [17] described a testing procedure based on the dynamic response of the cracked or flawed concrete structures subjected to impact loading and on analyzing the ability of the resistivity measurement to detect and to locate cracks and spalling with in situ measurements on a damaged concrete slab. Huang et al. [9] developed a SonReb (the combination of rebound hammer and ultrasonic pulse velocity tests), for compressive strength prediction of concrete samples, using a probabilistic multivariate regression model, taking into account the data of the proportions of the concrete mix (curing conditions and the age of the concrete), assessing the model from Bayesian updating rule. Lui et al. [18] provide a very wide state-of-the-art report regarding NDT data fusion techniques. They established the use of multiple NDT methods to increase the reliability and reduce the uncertainty of testing and evaluation. Nonetheless, there are cases in which the use of all available tests creates a model that only works in the samples used to empirically correlate the obtained data, and thus the model does not generalize. In order to deal with this problem, it is necessary for an automatic method of variable selection (here variables are the NDT) to establish a simple model that achieves the prediction/explanation of the response variable, together with an efficient estimation of the coefficients.

Given that there are only 6 different variables to create the model, in this contribution, a decision was made to test all the linear combinations of these variables, that is, create 64 models. The model proposed was selected from these 64 models by using a cross-validation technique. Furthermore, to illustrate the generality of the model, few samples were removed from the model formulation and selection process, and the results presented on this contribution are computed using the removed samples to validate the predicted model. Clearly, there are situations where it is not possible to compare all possible models. To provide a complete picture of this scenario, it was decided to use a cross-validation technique to select the best from the different 64 models.

In addition to this, in order to compare the proposed model against the ones described in the literature, a comparison was made with more than ten different models against the ones proposed here. The results show that the model proposed here is competitive with the ones proposed in previous investigations. In addition, the independent variables used in this investigation were used also with the other models found in the literature. With this extended set of independent 
variables, all the possible linear modes were initiated and used the selected mechanism to identify the best model. The result observed was that this novel model is competitive when compared against other models previously reported. However, the proposed model has a better correlation factor and was simpler in the sense that it has fewer degrees of freedom.

In this study, different frameworks to predict the $f^{\prime} c$ and the MOR of hydraulic concrete were constructed, based on data from electrical resistivity test (ERT), ultrasonic pulse (UPV), resonance frequency test (RFT), and rebound number test (RNT), obtained from cylindrical and prismatic specimens.

The objective of this research was to predict the $f^{\prime} c$ and MOR of concrete, since these are index parameters that determine the quality of the concrete, but with the use of models based on NDT. By employing more than one NDT, it has been possible to generate highly reliable and accurate models, as demonstrated herein. Furthermore, the obtained models can help engineers to understand how each one of the different variables, in the determination of the compressive strength and modulus of rupture, is important, either in laboratory samples or in samples from the place (field samples). This research was conducted in two stages: the first was controlling workability of the concrete, and the second one was controlling water/cement (w/c) ratio.

\section{Review of the Utilized NDT}

2.1. Electrical Resistivity Test (ERT). The application of DC current to quantify resistivity was performed by Conard Schlumberger in 1912. It was reported as one of the most successful experimental approach of electrical resistivity survey. In USA, the idea was developed by Frank Wenner in 1915. After that, the method has undergone significant improvement in last three decades [19].

Later Robert W. Fox in 1930 observed electric currents flowing in the copper mines in Cornwall, as a result of chemical reactions within the veins of the deposits [20]. In terms of materials and equipment, the ERT can be performed in laboratory specimens, in specimens taken from the analyzed structure, or directly in the structure at the site field [21]. ERT measurements are made by applying a current to a porous body, through two current electrodes, and measuring the resulting difference voltage at two potential electrodes. The test must be performed in saturated samples, under the mechanism of electrical conductivity through saturated connected pores, which is based on the conductivity of the water through the pores of the material [22]. Liu et al. [23] conducted a study in soil-cement, used to improve the behavior of soft soils in road construction engineering; they built a model to verify the quality control of soil-cement in the field. The model predicted the electrical resistivity (ER) of soil-cement, under certain conditions of curing time and the w/c ratio. It was found that the ER had a good relationship with the $f^{\prime} c$ of the material in study. Cao and Chung [24] presented a research in dynamic response of cement mortars, subjected to repeated cycles of $f^{\prime} c$ by measuring ER. Lataste et al. [25] used the ERT technique to characterize damage in field concrete structures, associated with the aperture and depth of surface cracks. On the other hand, for routine quality control measures, more rapid but also reliable methods are needed. Recent studies confirm that electrical resistivity measurement is a simple, reliable, and rapid test method for quality control of concrete $[26,27]$. Concrete has a resistivity varying substantially depending on a number of factors. The electrical current is carried by the dissolved charged ions flowing through the pore solution in the concrete. Therefore, all the factors such as water/cement ratio, cement type, pozzolanic admixtures, and degree of hydration that is affecting the pore structure of the concrete are also affecting the electrical resistivity of the concrete. Environmental factors such as temperature and moisture conditions can also have a large impact on the electrical resistivity of the concrete [26].

2.2. Ultrasonic Pulse Velocity (UPV). The UPV has been successfully used to evaluate the quality of hydraulic concrete for over 60 years. The $f^{\prime} c$ of concrete specimens and of concrete in situ can also be estimated through the test UPV $[28,29]$. Ultrasonic waves are mechanical waves that are generated by exciting a piezoelectric crystal with a high voltage pulse. The wave is then transmitted through the tested material, which is in contact with the transducer containing the crystal. When this wave impinges upon a receiving transducer, it produces an output voltage [30]. There are three possible ways in which the transducers may be arranged: direct transmission, semidirect transmission, and indirect transmission. In the direct method the transducers are placed on opposite faces of the tested element. In the semidirect method the transducers are placed at a $90^{\circ}$ angle whereas in the indirect method both transducers are placed on one face of the tested element. Since the transmission path length and direction are not well defined in the indirect method, the results produced are less satisfactory. Thus, the indirect method does not give any information on deeper concrete; it only collects information on the surface [31].

In order to use the UPV, a pulse of ultrasonic wave through the concrete is created at a point in the test object surface, and the time it takes to travel from that point to another is measured. Knowing the distance between these two points, the pulse wave velocity can be determined [28]. A lot of research has been conducted in order to use this technique to predict the mechanical properties of concrete and rock; for example, Wu and Lin [32] and Selleck et al. [33] investigated the behavior of UPV associated with the damage of concrete. When a solid medium is altered by a dynamic or vibratory load, three kinds of mechanical waves are generated; these waves can be classified by the way they propagate, (also called stress waves): (1) compression waves (also called longitudinal or P waves), (2) shear waves (also called S waves), and (3) surface waves (also known as Rayleigh waves) [34]. The velocity of such waves depends on the elastic properties of the medium, so that, knowing the speed of sound and the solid mass, it can estimate the elastic properties of the medium, which can be associated with the quality parameters of the material [35]. The relationship between the $f^{\prime} c$ and UPV is not unique, and it is affected by many factors such as the size, type, and content of aggregate, w/c ratio, 
and content of humidity. The effect of these factors has been studied by many researchers, who have clearly indicated that there should be estimated $f^{\prime} c$ of the concrete values from the UPV, unless these have similar correlations previously established for the type of concrete studied [36-40].

2.3. The Resonance Frequencies Test (RFT). The method for determining the dynamic modulus of elasticity of solid bodies, from their resonance frequencies, has been used in the last 55 years. However, in recent years, methods of the RFT have been used almost exclusively in laboratory studies [28].

In the late 1930s and early 1940s, other researchers improved the method by using electronic equipment for measuring the resonant frequency [41-43]; currently, this type of equipment is required by ASTM C 215-85 Standard Test Method [44]. The apparatus consists mainly of two sections: one generates mechanical vibrations and the other detects these vibrations [45]. The mechanical vibrations are detected by a piezoelectric transducer and it converts the mechanical vibrations into electric voltage alternating current of the same frequencies [28].

The great advantage of the vibrational methods of testing, apart from their nondestructive nature, is that the dynamic values are obtained from transient loads far below the elastic limit, so that the results are free from time-dependent inelastic strains and hysteresis and are directly related to the internal structure of the material [46].

Vibration-based techniques can be used to monitor the concrete structures. Bagchi et al. applied cost-effective and easy to implement vibration-based damage identification (VBDI) techniques for structural health monitoring of a bridge, based on changes in the dynamic characteristics of a structure to determine the location and extent of damage in the structure. Hsieh et al. described the use of vibrational monitoring in the field of structural analysis for detecting and locating structural damage for the purpose of structural health monitoring $[47,48]$.

On the other hand, the measurement of the dynamic modulus of elasticity with resonance frequency method predictions can be made about the damage degree and deleterious progress, respectively. The dynamic moduli and the damping capacity are the two important properties of engineering materials obtained from vibrational methods of testing. To ensure stability and long life it is necessary to avoid the large amplitudes of vibration associated with resonant frequencies. However, where the nature of the structure and its environment are beyond the control of the designer, the amplitude of vibration at resonance depends on the damping capacity of the structure and its mounting. Knowledge of both the dynamic moduli and the damping characteristics of cementitious materials is thus an important aid to design [46].

2.4. Rebound Number Test (RNT). The RNT method is performed through the device called sclerometer (Schmidt Hammer Rebound). It is based on the principle that the rebound of an elastic mass depends on the hardness of the surface against which the hammer hits; there is a relationship of proportionality between the resistance of concrete and the rebound height of the hammer mass, which is measured by an arbitrary scale of integer numbers. Within certain limits, empirical correlations have been established between the properties of strength of concrete and the RNT [45]. The RNT provides information about the strength of the material near the surface where the test is performed; rebound number (RN) is an indicator of the mechanical properties of the material. Although a large rebound number represent a concrete with a higher compressive strength than a concrete with a low rebound, the test is only useful if a relationship can be established between the rebound number and the analyzed resistance of the concrete, assuming that concrete samples have been made with the same type of stone aggregates [10].

For estimation of compressive strength of concrete in structures that are using different testing procedures, compressive strength of concrete can be found as follows: destructive by taking core bore samples from a structure; nondestructive by Schmidt rebound hammer or ultrasonic pulse velocity method; semidestructive test methods or a combination of destructive and nondestructive testing. Standard procedures have been established and are described in detail in European and international standards as European standards: CSN EN 12504-2 [49] and Czech technical standard: CSN 731373 [50] and standards as ASTM C 805-97 [51], JGJ/T 23-2001 [52].

The combination of NDT such as UVP and RNT can be conducted to assess the resistance of the concrete in situ. This combination has an advantage; the Sclerometer reveals information regarding the concrete surface, while ultrasound provides information from the inside of the material [9]. In technical literature, there are models proposed by several authors [9, 11, 53-62]. Table 1 summarizes the proposed equations to have a fair comparison.

Carbonation of concrete occurs when the carbon dioxide, in the atmosphere in the presence of moisture, reacts with hydrated cement minerals to produce carbonates, for example, calcium carbonate. In this case, the research was carried out with hydraulic concrete with ages from 3 to 28 days. Period during which did not exist the necessary conditions for carbonation should arise in concrete. However we can say that, in older concrete, the carbonation depth can be several millimeters thick and, in extreme cases, up to $20 \mathrm{~mm}$ thick. In such cases the rebound numbers can be up to $50 \%$ higher than those obtained on an uncarbonated concrete surface. In such cases it is necessary to make an adjustment to the obtained rebounds [10]. Moisture condition type of aggregate and carbonation depth of the material can affect the strength estimate [63] and some standards (e.g., Chinese standards JGJ/T 23-2001) offer recommendations for compensating these effects [52].

\section{Significance of Current Research}

Nowadays it has been recognized that NDT plays an important role in the condition monitoring of civil infrastructures. To properly maintain the civil infrastructures integrity, engineers required new methods of inspection. Better inspection techniques are needed for damaged infrastructure [64]. Being aware of this problem, in this study, four nondestructive 
TABLE 1: Evaluation of different models proposed by different authors.

\begin{tabular}{llc}
\hline Model & Formulation & Correlation factor $(R)$ \\
\hline$M_{0}[9]$ & $f^{\prime} c=\theta_{0}+\theta_{1} N R^{2}+\theta_{2} \mathrm{UPV}+\theta_{3} w c^{-0.5}+\theta_{4} \ln ($ age $)+\varepsilon$ & 0.638 \\
$M_{0 a}[9]$ & $f^{\prime} c=\theta_{0}+\theta_{1} N R^{2}+\theta_{2} \mathrm{UPV}^{3}+\varepsilon$ & 0.614 \\
$M_{1}[53,71]$ & $f^{\prime} c=\theta_{0}+\theta_{1} R+\theta_{2} \mathrm{UPV}$ & 0.621 \\
$M_{2}[54]$ & $f^{\prime} c=\theta_{0}+\theta_{1} R^{3}+\theta_{2} \mathrm{UPV}$ & 0.616 \\
$M_{3}[11]$ & $f^{\prime} c=\theta_{0}+\theta_{1} R+\theta_{2} \mathrm{UPV}$ & 0.612 \\
$M_{4}[55]$ & $f^{\prime} c=\theta_{0}+\theta_{1} R+\theta_{2} \mathrm{UPV}+\theta_{3} \mathrm{UPV}^{2}$ & 0.596 \\
$M_{5}[56,58,61]$ & $\ln f^{\prime} c=\theta_{0}+\theta_{1} R+\theta_{2} \mathrm{UPV}$ & 0.613 \\
$M_{6}[59,60]$ & $\ln f^{\prime} c=\theta_{0}+\theta_{1} \ln R+\theta_{2} \ln \mathrm{UPV}$ & 0.617 \\
$M_{7}[57]$ & $\ln f^{\prime} c=\theta_{0}+\theta_{1}\left(\sqrt{\ln \left(N R^{3} * \mathrm{UPV}\right)}\right)$ & 0.599 \\
$M_{8}[62]$ & $f^{\prime} c=\theta_{0}+\theta_{1} R^{-1}+\theta_{2}\left(\mathrm{UPV} * R^{-1}\right)$ & 0.600 \\
$E_{a}$ & $f^{\prime} c=\theta_{0}$ freq $+\theta_{1}$ rebound $+\theta_{2}$ resistiv $+\theta_{3} \mathrm{UPV}$ & 0.636 \\
$E_{b}$ & $f^{\prime} c=\theta_{0}+\theta_{1} N R^{2}+\theta_{2} \mathrm{UPV}+\theta_{3}(\mathrm{w} / \mathrm{c})^{-0.5}+\theta_{4} \ln ($ age $)+\theta_{5}$ resistiv $+\theta_{6}$ freq $+\varepsilon$ & 0.642 \\
\hline
\end{tabular}

techniques were used to predict two important properties to consider in a structure needed for proper maintenance or to know the service conditions of the structure of hydraulic concrete $\left(f^{\prime} c\right.$ and MOR). By combining several nondestructive techniques, robust models that improve the accuracy of the model were generated. In addition, in situ performance conditions are different from controlled laboratory conditions and, so, it is difficult to keep strict quality control.

In this paper, the conditions of both field and laboratory for concrete mixtures under study were obtained as reported in Section 4; the forecast mathematical frameworks were generated taking into account these conditions and finally they were fed with data from nondestructive and destructive tests, so these models will have better attachment to the reality. Furthermore a methodology that could be applied to any situation to generate and apply a particular model in the prediction of the properties of the structure under study could be chosen by the particular characteristic of the research material.

And inasmuch as that we can demonstrate the reliability of nondestructive techniques for the analysis and inspection of concrete structures, we will be providing an important tool for engineers that can be exploited to save and optimize resources.

\section{Experimental}

The experimental study was divided in two stages. The first one developed three types of specimens: type I: 70 cylinders with dimensions of $100 \mathrm{~mm}$ (3.94 in) diameter and $200 \mathrm{~mm}$ (7.87 in) height; type II: 70 cylinders with dimensions of $150 \mathrm{~mm}$ (5.91 in) diameter and $300 \mathrm{~mm}$ (1.81 in) height; type III: 20 beams with dimensions of $150 \mathrm{~mm} \times 150 \mathrm{~mm}$ $\times 600 \mathrm{~mm}(5.91$ in $\times 5.91$ in $\times 23.62$ in $)$. All samples were prepared per ASTM C-143 requirements [65] as reported in Table 2 . The w/c ratio varied from 0.55 to 0.76 , simulating field concrete specimens. In the second stage, three other types of specimens were developed with the same dimensions to that in the first stage, but with other w/c ratios: type I: 70 cylinders; type II: 70 cylinders; and type III: 40 beams, half of each type
TABLE 2: Slumps of mixtures made.

\begin{tabular}{|c|c|c|c|}
\hline Mixture & $\mathrm{w} / \mathrm{c}$ & $\begin{array}{c}\text { Project } \\
\text { slump } \\
\mathrm{mm} \text { (in) }\end{array}$ & $\begin{array}{l}\text { Obtained } \\
\text { slump } \\
\text { mm (in) }\end{array}$ \\
\hline \multicolumn{4}{|c|}{ First stage } \\
\hline 1 & 0.55 & $75(2.95)$ & $100(3.94)$ \\
\hline 2 & 0.61 & $100(3.94)$ & $135(5.31)$ \\
\hline 3 & 0.57 & $75(2.95)$ & $115(4.53)$ \\
\hline 4 & 0.76 & $100(3.94)$ & $190(7.48)$ \\
\hline \multicolumn{4}{|c|}{ Second stage } \\
\hline 1 & 0.50 & 75 (2.95) & $85(3.35)$ \\
\hline 2 & 0.65 & $100(3.94)$ & $145(5.71)$ \\
\hline
\end{tabular}

specimens were made up with $\mathrm{w} / \mathrm{c}=0.65$ and the rest with $\mathrm{w} / \mathrm{c}=0.50$. These specimens were labeled as concrete made in the laboratory. Table 3 summarizes the measurements of the NDT performed on the specimens, that is, ERT, RFT, UPV, and RNT; the DTs values are also included in the table, $f^{\prime} c$ and MOR. It should be noted that all the test specimens were performed under saturated conditions; for structures in situ special equipment is needed for locating the presence of the reinforcing steel and performing the readings of NDT on places away from reinforcing steel to avoid possible errors due to the presence of it $[66,67]$.

When NDTs were completed some of the specimens were selected and scheduled for destructive testing. In the first stage of the investigation, 5 cylinders type I, 5 cylinders type II, and 2 beams from each different mixture (see Table 2 ) were tested. In the second stage only 3 cylinders type I, 3 cylinders type II, and 2 beams were tested due to the assumption that these samples were made in laboratory conditions; therefore, it can be assumed that there is less dispersion of the data from "laboratory" with respect to the information from the "field". The tests were performed at 3, 7, 14, 21, and 28 days. The $f^{\prime} c$ and MOR values of hydraulic concrete were calculated in accordance with ASTM $[1,2]$; the tests were performed 
TABLE 3: Nondestructive and destructive testing applied to the specimens.

\begin{tabular}{|c|c|c|c|c|c|c|c|}
\hline \multirow{2}{*}{ Specimen } & \multirow{2}{*}{$\begin{array}{l}\mathrm{w} / \mathrm{c} \\
\text { ratio }\end{array}$} & \multicolumn{4}{|c|}{ NDTs } & \multicolumn{2}{|c|}{$\mathrm{DT}$} \\
\hline & & ERT & UPV & RNT & RFT & $f^{\prime} c$ & MOR \\
\hline \multicolumn{8}{|c|}{ STAGE I } \\
\hline \multirow{4}{*}{ Type I } & 0.55 & $\mathrm{X}$ & $\mathrm{X}$ & $\mathrm{X}$ & $\mathrm{X}$ & $\mathrm{X}$ & \\
\hline & 0.57 & $\mathrm{X}$ & $\mathrm{X}$ & $\mathrm{X}$ & $\mathrm{X}$ & $\mathrm{X}$ & \\
\hline & 0.61 & $\mathrm{X}$ & $\mathrm{X}$ & $\mathrm{X}$ & $\mathrm{X}$ & $\mathrm{X}$ & \\
\hline & 0.76 & $\mathrm{X}$ & $\mathrm{X}$ & $\mathrm{X}$ & $\mathrm{X}$ & $\mathrm{X}$ & \\
\hline \multirow{4}{*}{ Type II } & 0.55 & $\mathrm{X}$ & $\mathrm{X}$ & $\mathrm{X}$ & $\mathrm{X}$ & $\mathrm{X}$ & \\
\hline & 0.57 & $\mathrm{X}$ & $\mathrm{X}$ & $\mathrm{X}$ & $\mathrm{X}$ & $\mathrm{X}$ & \\
\hline & 0.61 & $\mathrm{X}$ & $\mathrm{X}$ & $\mathrm{X}$ & $\mathrm{X}$ & $\mathrm{X}$ & \\
\hline & 0.76 & $\mathrm{X}$ & $\mathrm{X}$ & $\mathrm{X}$ & $\mathrm{X}$ & $\mathrm{X}$ & \\
\hline \multirow{4}{*}{ Beam } & 0.55 & & $\mathrm{X}$ & & $\mathrm{X}$ & & $\mathrm{X}$ \\
\hline & 0.57 & & $\mathrm{X}$ & & $\mathrm{X}$ & & $\mathrm{X}$ \\
\hline & 0.61 & & $\mathrm{X}$ & & $\mathrm{X}$ & & $\mathrm{X}$ \\
\hline & 0.76 & & $\mathrm{X}$ & & $\mathrm{X}$ & & $\mathrm{X}$ \\
\hline \multicolumn{8}{|c|}{ STAGE II } \\
\hline \multirow{2}{*}{ Type I } & 0.50 & X & $\mathrm{X}$ & & $\mathrm{X}$ & $\mathrm{X}$ & \\
\hline & 0.65 & $\mathrm{X}$ & $\mathrm{X}$ & & $\mathrm{X}$ & $\mathrm{X}$ & \\
\hline \multirow{2}{*}{ Type II } & 0.50 & $\mathrm{X}$ & $\mathrm{X}$ & & $\mathrm{X}$ & $\mathrm{X}$ & \\
\hline & 0.65 & $\mathrm{X}$ & $\mathrm{X}$ & & $\mathrm{X}$ & $\mathrm{X}$ & \\
\hline \multirow{2}{*}{ Beam } & 0.50 & $\mathrm{X}$ & $\mathrm{X}$ & & $\mathrm{X}$ & & $\mathrm{X}$ \\
\hline & 0.65 & $\mathrm{X}$ & $\mathrm{X}$ & & $\mathrm{X}$ & & $\mathrm{X}$ \\
\hline
\end{tabular}

TABLE 4: Materials used in concrete mixtures.

\begin{tabular}{lc}
\hline Material & Type \\
\hline Cement & CPC 30R RS, NMX C 414-22010 \\
Sand & Type II, ASTM C150 \\
Gravel & Volcanic \\
Water & Volcanic \\
\hline
\end{tabular}

by means of a universal testing machine with a capacity of $1471 \mathrm{KN}$ and $0.10 \mathrm{KN}$ of approximation.

4.1. Materials. Materials used are summarized in Table 4. The concrete design was performed as ACI requirements [4]. The cement used was CPC 30R RS, according to the Mexican standard NMX C 414-22010 [68], being equivalent to Type II of ASTM C150 [69]. The mixtures were designed for $f^{\prime} c=$ $24.52 \mathrm{MPa}$ and $f^{\prime} c=16.67 \mathrm{MPa}$.

\section{Modeling the Compressive Strength $\left(f^{\prime} c\right)$ and Modulus of Rupture (MOR)}

As mentioned above, the contribution of this paper is to predict the $f^{\prime} c$ and MOR, by proposing a linear equation (1), which combines data obtained through four different
NDTs: ERT, UPV, RFT, and RNT. The following model was proposed:

$$
\begin{aligned}
y= & a_{0}+a_{1} \mathrm{ERT}+a_{2} \mathrm{UPV}+a_{3} \mathrm{RFT} \\
& +a_{4} \mathrm{RNT}+a_{5} \text { age }+a_{6} \mathrm{w} / \mathrm{c}
\end{aligned}
$$

where $a_{i}$ are the coefficients to be calculated and $y$ is either the compressive strength $f^{\prime} c$ or the modulus of rupture MOR in $\mathrm{MPa}$.

Even though it was decided to produce the model using a linear equation, it is the possibility that one or some of these NDTs were not correlated with the characteristic being modeled (in this case $f^{\prime} c$ or MOR). If this were the case, their inclusion in the model would not be beneficial. For example, let us suppose that all the available variables are used; however, one of these is not correlated with the characteristic being predicted. In this case, it would see that the accuracy of the model on the specimens used to identify the coefficient is the poorest. Unfortunately, given that one test is not correlated with response, then the accuracy of this model on different specimens is not as good as the performance of a model that does not include this noncorrelated test; that is, a model with poor generality can be calculated.

In order to overcome this problem, was decided to create all the linear models that can be built using the available independent variables. Then, our proposed model was identified by following the next procedure. That is, in order to identify the final model, a one-leave-out technique [70] is used in a subset of the total number of specimens. This is performed as follows: let $n$ be the number of specimens, in this subset, used to identify the coefficients of a particular model; then $n-1$ specimens are used to identify the coefficients of that model using ordinary least squares, and, then, this model is used to predict the characteristic of the missing specimen. This process is repeated for all the specimens; at the end of this process, the predicted values are compared against the actual values, and, as consequence, the generality of the model is assessed. This procedure is repeated for all the available models and at the end the model selected is the one that presents the best generality.

\section{Results and Discussion}

Comparative graphs of the mechanical properties measurements against nondestructive tests carried out were plotted; they were constructed with the point values of the readings recorded for each mixture at different ages $(3,7,14,21$, and 28 days). Figure 1(a) shows the scatter plot of the ERT measurements versus the $f^{\prime} c$ values of cylinders types I and II for the concrete considered as made in situ. This figure is representative of the results obtained in this stage of research. In these samples the ERT increases with the age; in spite of the fact that this is a general trend, where a substantial dispersion of the plotted data is shown. Figure 1(b) shows the representative results of the cylinders types I and II of the second stage (concrete made in the laboratory); unlike the results shown in Figure 1(a), there is a definite upward trend, where the mechanical properties of concrete increase with age and therefore also increase the ERT. The mixtures of the 


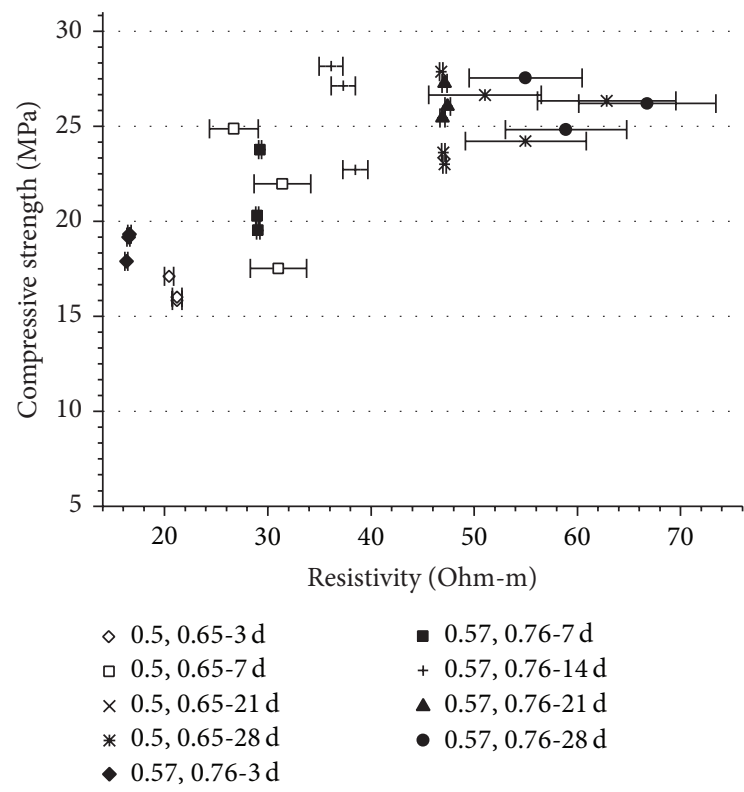

(a)

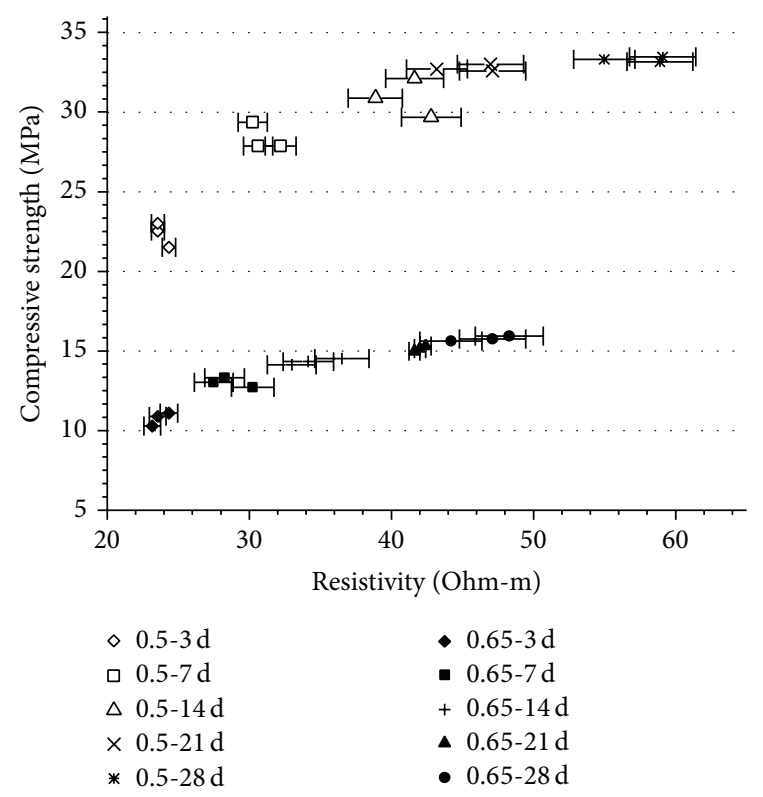

(b)

FIGURE 1: Compressive strength versus electrical resistivity of cylinder type I with w/c ratio = (a) $0.55,0.57,0.61$, and 0.76 (concrete made in situ) and (b) 0.50 and 0.65 (concrete made in laboratory) for ages of 3 days to 28 days.

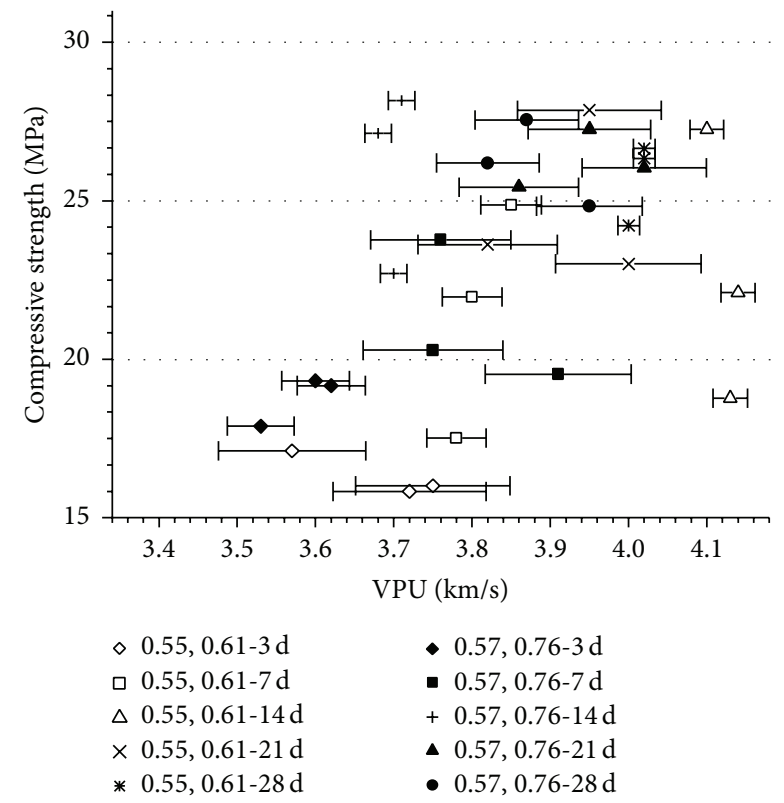

(a)

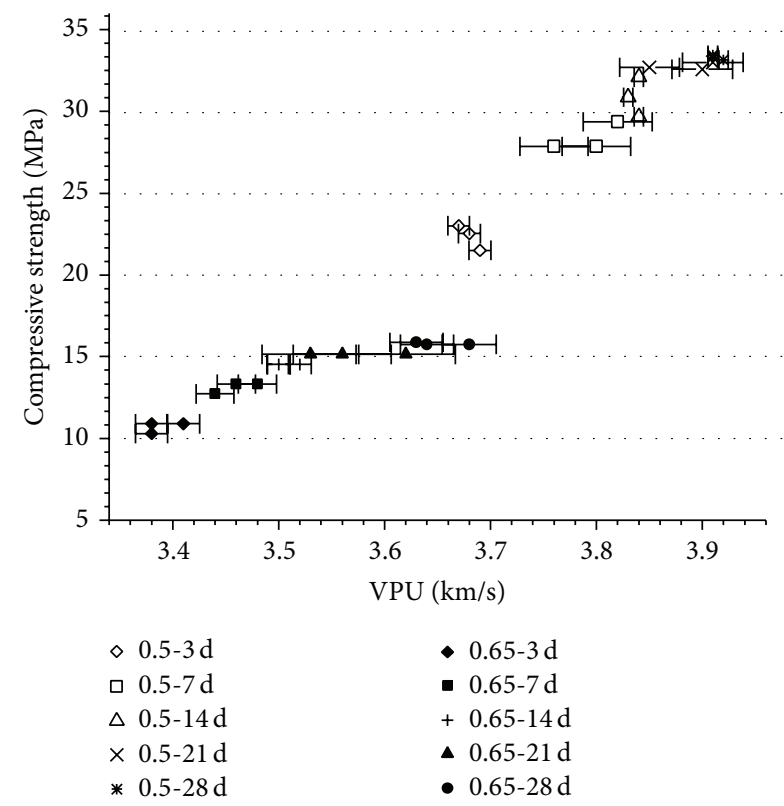

(b)

FiguRE 2: Compressive strength versus ultrasonic pulse velocity of cylinder type I with $\mathrm{w} / \mathrm{c}$ ratio $=$ (a) $0.55,0.57,0.61$, and 0.76 (concrete made in situ) and (b) 0.50 and 0.65 (concrete made in laboratory) for ages of 3 days to 28 days.

second stage with $\mathrm{w} / \mathrm{c}=0.65$ have a lower ERT than mixtures with $\mathrm{w} / \mathrm{c}=0.50$ due to the content of interconnected saturated pores through which the electric current flows; this is being reflected in the results shown.

The behavior described by the ERT is very similar to the one observed for the UPV (Figure 2). The results obtained with the RFT showed no trend. Figure 3 shows representative results obtained on cylinders type I and II at both stages of the investigation, this graph corresponds to cylinders type II with $\mathrm{w} / \mathrm{c}$ ratio $=0.50$ and ages of 3 to 28 days; any trend is not observed in such a graph.

On the other hand, the graphs that correspond to the beams of the first stage have a FRT in longitudinal mode that describes an upward trend with respect to the increase 
TABLE 5: Comparison of models obtained to predict $f^{\prime} c$ and MOR.

\begin{tabular}{|c|c|c|c|}
\hline Samples & Models & $\begin{array}{l}\text { Factor } \\
\text { correl. }\end{array}$ & Name. \\
\hline $\begin{array}{l}\text { Cyl. of 1st and } 2 \text { nd stage, } 27 \mathrm{cyl} \text {. } \\
\text { used for validation }\end{array}$ & $f^{\prime} c=\theta_{0}$ freq $+\theta_{1} \mathrm{UPV}+\theta_{2}(\mathrm{w} / \mathrm{c})+\theta_{3}$ resistiv & 0.895 & $E_{0}$ \\
\hline $\begin{array}{l}\text { Cyl. of } 1 \text { st and } 2 \text { nd stage, } 27 \mathrm{cyl} \text {. } \\
\text { used for validation. }\end{array}$ & $f^{\prime} c=\theta_{0}+\theta_{1} \mathrm{UPV}^{3}+\theta_{2}(\mathrm{w} / \mathrm{c})^{-0.5}+\theta_{3} \ln ($ age $)+\theta_{4}$ resistiv $+\theta_{5}$ freq $+\varepsilon$ & 0.889 & $E_{1}$ \\
\hline Beams of 1st and 2nd stage. & $\mathrm{Mr}=\theta_{0}$ age $+\theta_{1}$ freq_long $+\theta_{2}(\mathrm{w} / \mathrm{c})+\theta_{3}$ freq_trans & 0.913 & $E_{2}$ \\
\hline
\end{tabular}

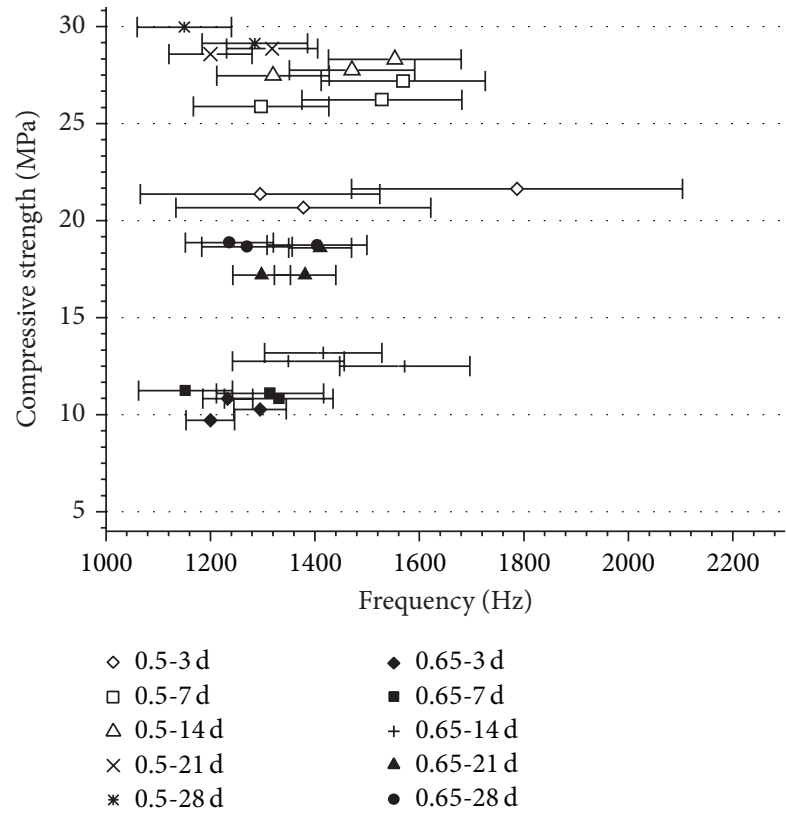

FIGURE 3: Compressive strength versus resonance frequency in longitudinal mode obtained in cylinders type II with $\mathrm{w} / \mathrm{c}$ ratio $=0.50$ and 0.65 for ages of 3 days to 28 days (concrete made in laboratory).

of the age (see Figure 4(a)), as in the case of ERT versus $f^{\prime} c$ (Figure 1(a)) and UPV versus $f^{\prime} c$ (Figure 2(a)); where a substantial dispersion of the plotted data is shown that also can be attributed to not controlling the $\mathrm{w} / \mathrm{c}$ ratio as described above (simulating concrete made in situ).

The FRT and longitudinal and transverse mode observed on beams of the second stage showed an increase of both the MOR and the FRT values as the age of the samples increased, the values for the longitudinal FRT of the beams with a $\mathrm{w} / \mathrm{c}$ ratio $=0.50$ are higher than the frequencies measured on the beams with a w/c ratio $=0.65$. Figure $4(\mathrm{~b})$ shows representative results obtained in beams of the second stage; there is an upward trend over the time.

The results obtained from $f^{\prime} c$ versus RNT in cylinders type I are shown in Figure 5; it is possible to try to define a trend indicating a rebound increase associated with the age of the concrete; however it can be observed a significant dispersion of data due to the fact that the w/c ratio was not controlled to simulate concrete made in situ; therefore, there are almost the same values of $f^{\prime} c$ at ages of 14,21 , and 28 days.
In the common situation where an assessment of material strength is required, it is unfortunate that the complexity of correlation tends to be greatest for the test methods which cause the least damage. Although rebound hammer test causes little damage, is cheap and quick, and is ideal for comparative and uniformity assessments, its correlation to absolute strength prediction poses many problems. Core tests provide the most reliable in situ strength assessment but also cause the most damage and are slow and expensive. However one of the advantages of this paper is the combination of several nondestructive tests to get models that provide better predictions.

Using the data recorded from first stage samples by the NDT, different models found in technical literature $[9,11,53-$ $62,71]$ were tested in order to compare other frameworks against the models developed herein. The coefficients of these models are identified using ordinary least squares and the predictions are computed using the Leave-one-out crossvalidation (LOOCV) technique. Their respective correlations factors were obtained using the information of the destructive tests (see Table 1). In order to facilitate the comparison, in this table, our proposed models $E_{a}$ and $E_{b}$ were also included. It is important to note that these proposed models were generated with the information of the first stage since at this stage we have the RNT. The models proposed in Table 5 (models $E_{0}$, $E_{1}$, and $E_{2}$ ) were generated with the information of the two stages, but eliminating the RNT because there were cylinders with RNT (first stage) and cylinders without RNT (second stage).

The model $E_{a}$ corresponds to a proposed model that takes into consideration only the four NDTs; it is a first degree equation with four variables and four constants, with a correlation factor of 0.636 . The model $E_{b}$ was generated taking the model $M_{0}$ [9] as a basis, but the ERT and RFT were added to the model; it is a third degree equation with six variables and seven constants, with a correlation factor of 0.642; the variables considered for this model are the NDT and the age and the $\mathrm{w} / \mathrm{c}$ ratio of the concrete. As can be observed, correlation factors for models $E_{a}$ and $E_{b}$ are very near to the values of the other frameworks; therefore, these two models can be considered as accurate enough for the predictions of the mechanical properties of concrete.

Table 5 summarizes our models for prediction of the $f^{\prime} c$ and MOR; the correlation factor values are indicated. The model was constructed with NDT data from both stages of the experimental study (90 cylinders randomly selected 


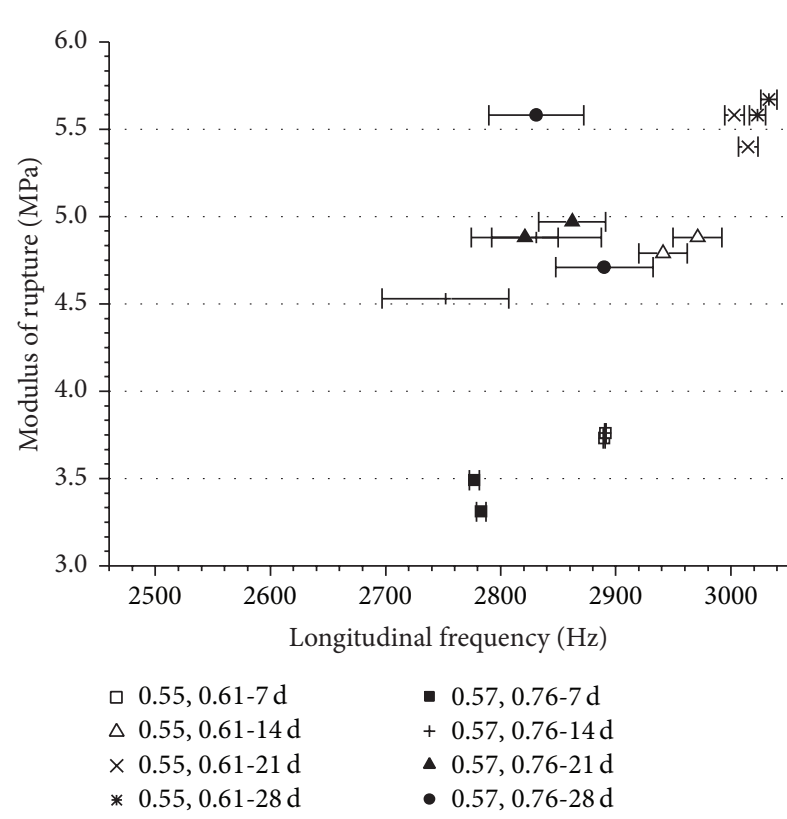

(a)

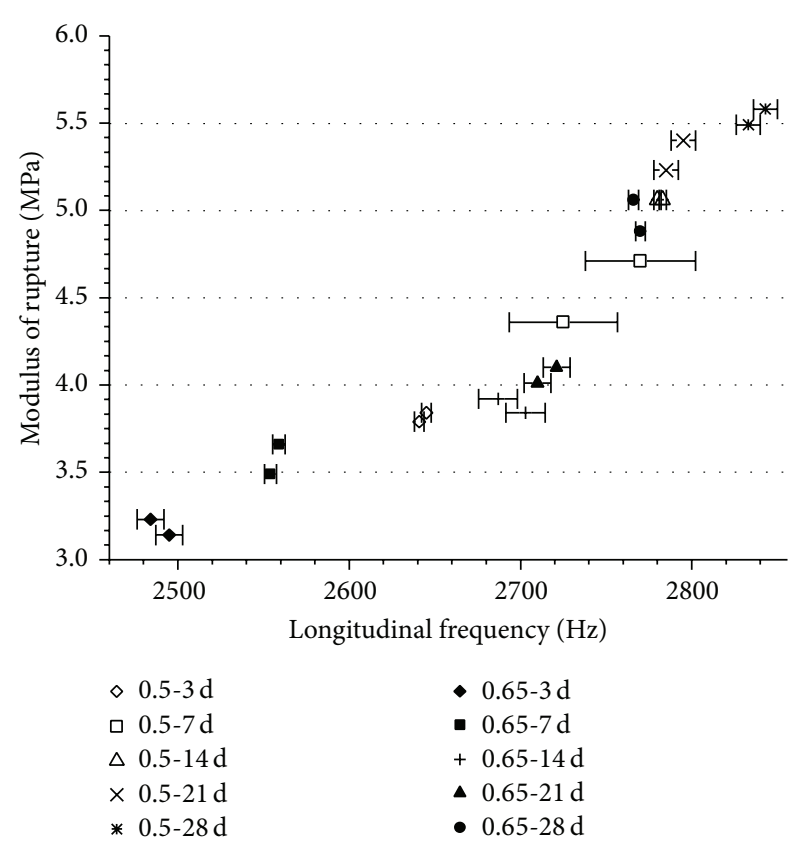

(b)

FIGURE 4: Modulus of rupture versus fundamental resonance frequency in longitudinal mode in beams with dimensions of $150 \mathrm{~mm} \times 150 \mathrm{~mm}$ $\times 600 \mathrm{~mm}$, with $\mathrm{w} / \mathrm{c}$ ratios $=($ a) $0.55,0.57,0.61$, and 0.76 (concrete made in situ) and (b) 0.50 and 0.65 (concrete made in laboratory) for ages of 7 day to 28 days.

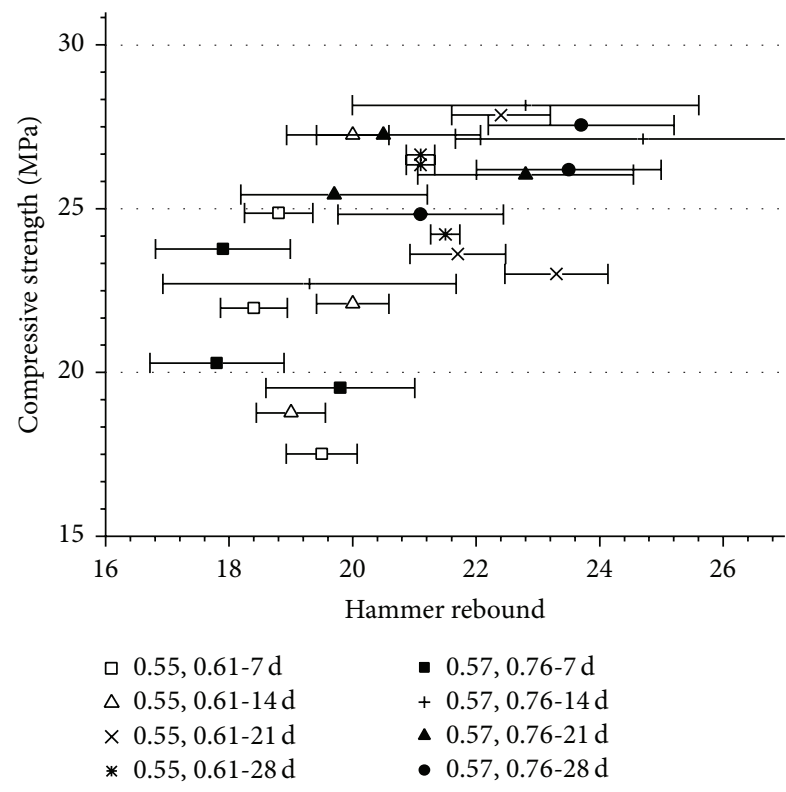

FIGURE 5: Compressive strength versus hammer rebound obtained in cylinders type I with $\mathrm{w} / \mathrm{c}$ ratio $=0.57$ and 0.76 for ages of 7 day to 28 days (concrete made in situ).

of the total of 117); due to the fact that the RNT was not performed on the second stage, it was necessary to remove such information in order to generate the models. Figures 6(a) and 6(b) present the correlation coefficient of these models in the training phase. In order to measure the generality of the models selected, a validation was conducted with information of NDT and DTs performed in the 27 remaining cylinders. The best models are summarized in Table 5.

Leave-one-out cross-validation (LOOCV) implies isolation of the data for each iteration, in such a manner that a single sample for the test data and the rest forming the training data are obtained. The evaluation is given by the error; in this type of cross-validation error is very low, but, in contrast, it is computationally very time consuming because the method has to make a large number of iterations, as many as $n$ samples and for each test data (test data and training data) [72].

From the cross-validation analysis, 64 models were obtained as a result of all possible combinations of the variables considered, 32 of type $E_{a}$ and 32 of type $E_{b}$; the two best to predict the $f^{\prime} c$ of the hydraulic concrete $\left(E_{0}\right.$ and $\left.E_{1}\right)$ are shown in Table 5 . The model $E_{0}$ is that in which the variables (NDT data) are multiplied by constants; the correlation factor is 0.886 which is greater than the correlation factor obtained by the model $E_{1}$, with a correlation factor of 0.858 . In case of the beams, models were generated to predict the MOR; in this case all the samples were used to generate and validate the models due to the small number of specimens. 32 models were generated obtaining their correlation coefficients (see Figure 6(c)). The best model is $E_{2}$ with a correlation factor of 0.913 as shown in Table 5. The predictions of the $f^{\prime} c$ obtained with the models $E_{0}$ and $E_{1}$ are shown in Figures $7(\mathrm{a})$ and $7(\mathrm{~b})$; the MOR predictions are shown in Figure 7(c). 

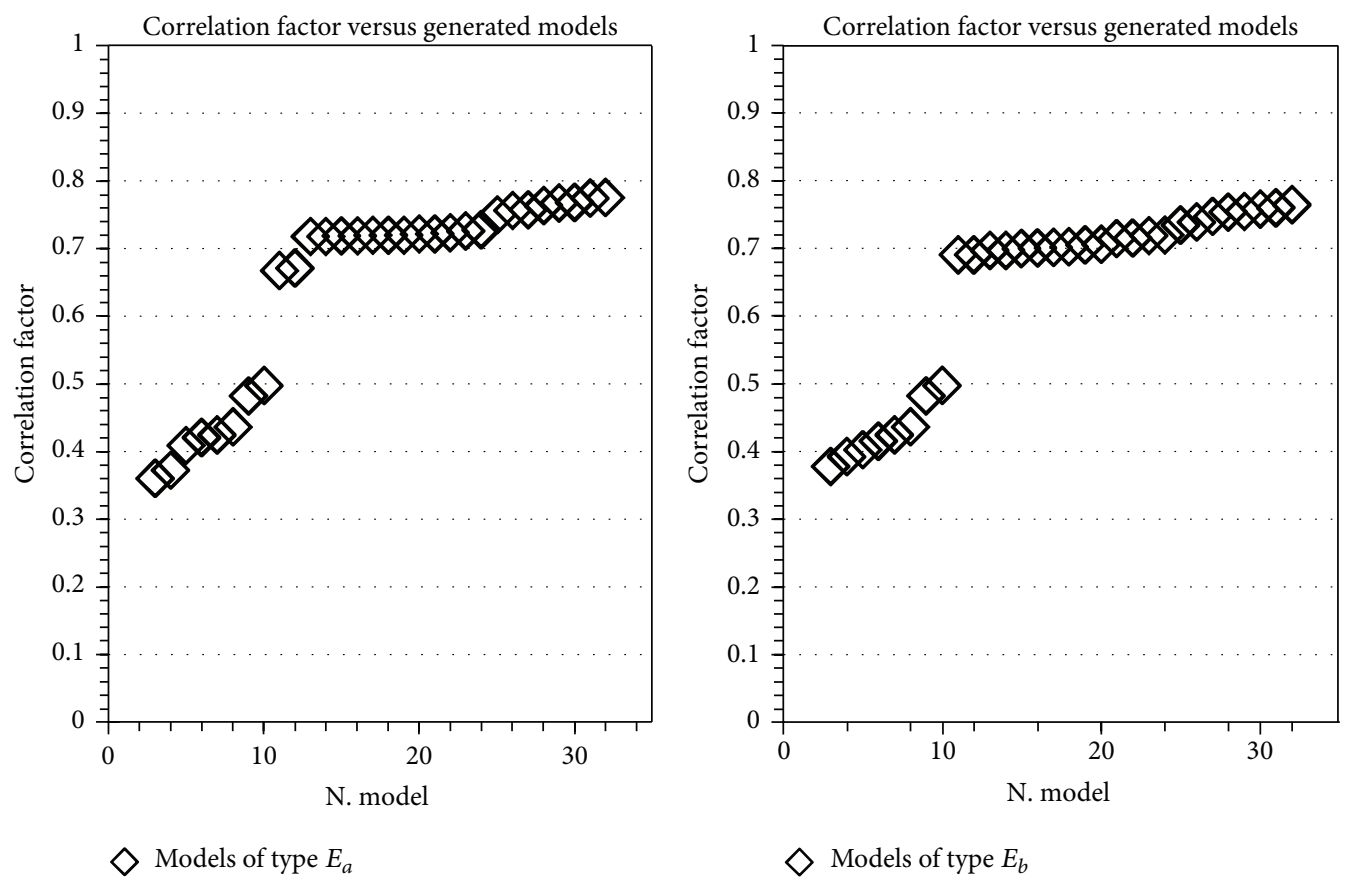

(a)

(b)

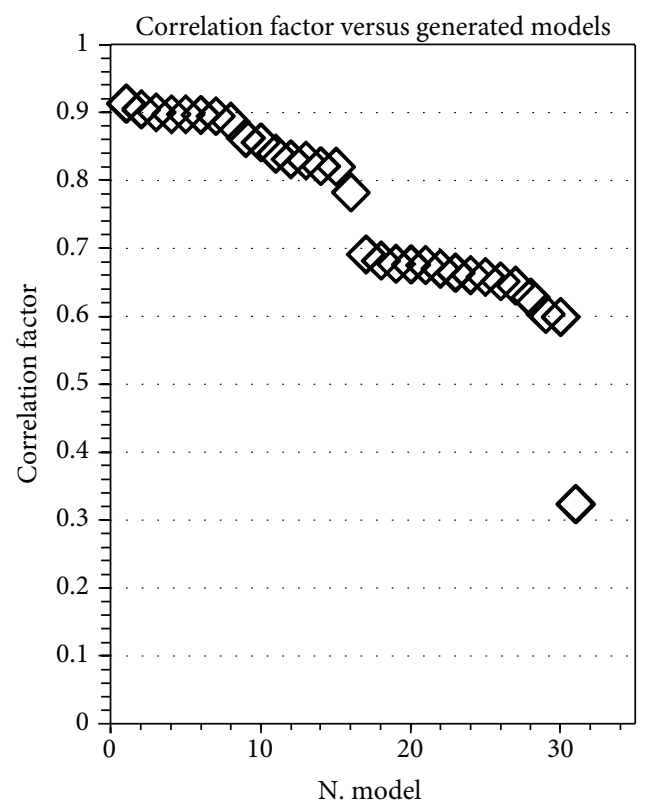

Models of beams

(c)

FIgURE 6: Correlation factor of the generated models: (a) of the type $E_{a}$ and (b) of the type $E_{b}$ with combined cylinders and (c) on beams.

Figure 8 presents the boxplot of the errors produced by the different models presented on this contribution, that is, $E_{0}, E_{1}$, and $E_{b}$. This figure is complemented with the boxplot of the error presented by model $M_{0}$ (see Figure 9). Comparing the boxplot on Figures 8(a), 8(b) and 9-which correspond to models of $f^{\prime} c$-it is observed that these boxplots are very similar indicating that these models are equivalent with respect to their error. Model $E_{1}$ has a higher variability indicated by the lines extending from the box; however, seeing the size of the box one can consider them similar.

6.1. Validation of the Models Using Test of Hypotheses. According to Walpole et al. [73], "A statistical hypothesis is an assertion or conjecture concerning one or more populations," 


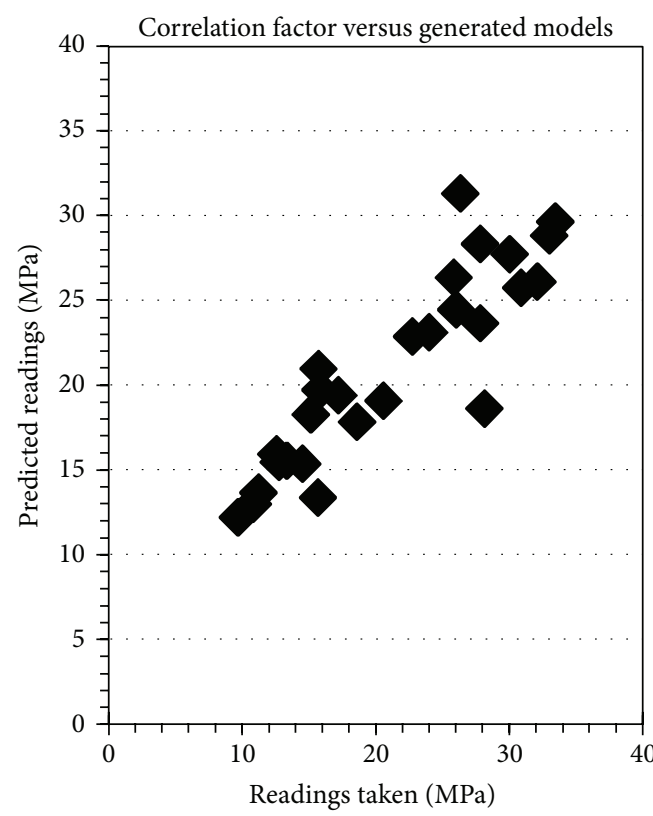

27 remaining cylinders

(a)

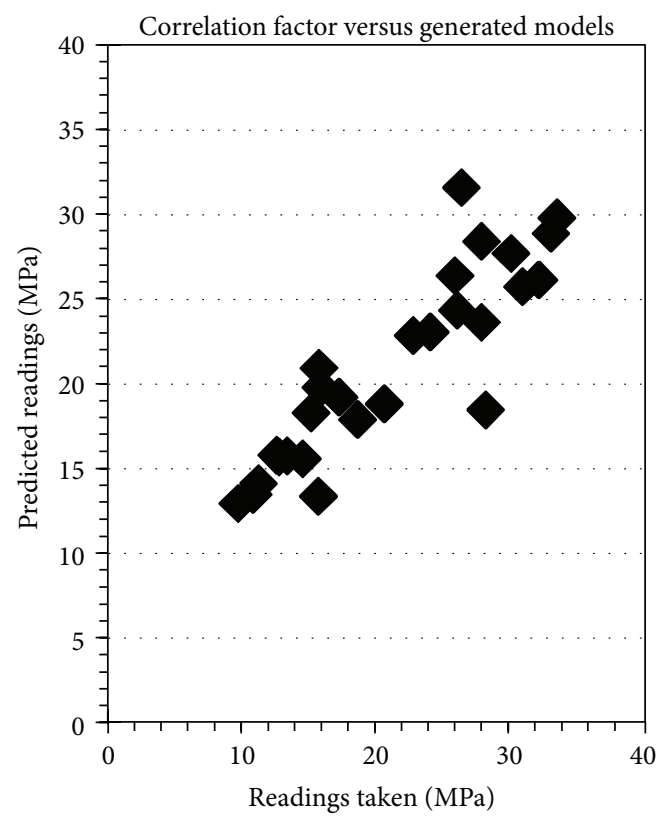

27 remaining cylinders

(b)

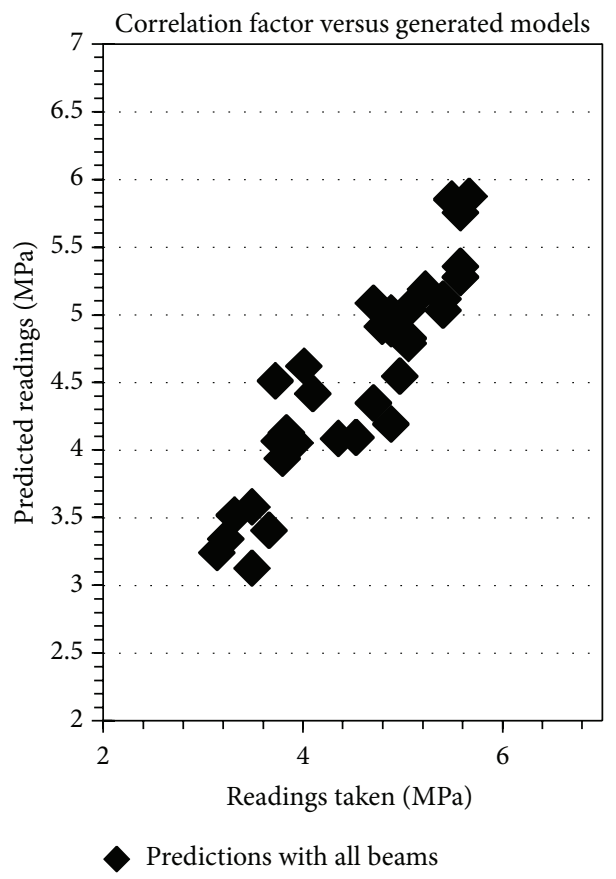

(c)

Figure 7: Predictions obtained with the models (a) $E_{0}$ and (b) $E_{1}$ for cylinders and (c) with the model $E_{2}$ for beams.

in our case, this assertion or conjecture is relative to defining whether or not the information predicted by the different calculated models is equivalent to the real values estimated by destructive testing.

In order to determine the validity of the prediction models we assumed a paired observations test of hypotheses; computation of the confidence interval for meanl-mean 2 in the situation with paired observations is based on the random variable, presented in (2) [73]:

$$
t=\frac{\bar{d}-d_{0}}{s_{d} / \sqrt{n}}
$$

where $\bar{d}$ and $s_{d}$ are random variables representing the sample mean and standard deviation of the differences of 


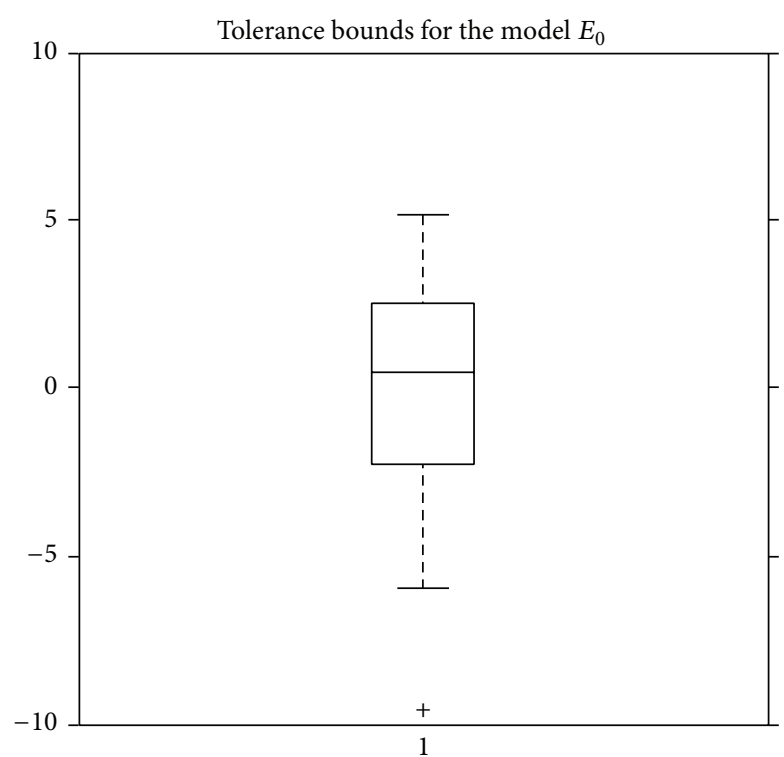

(a)

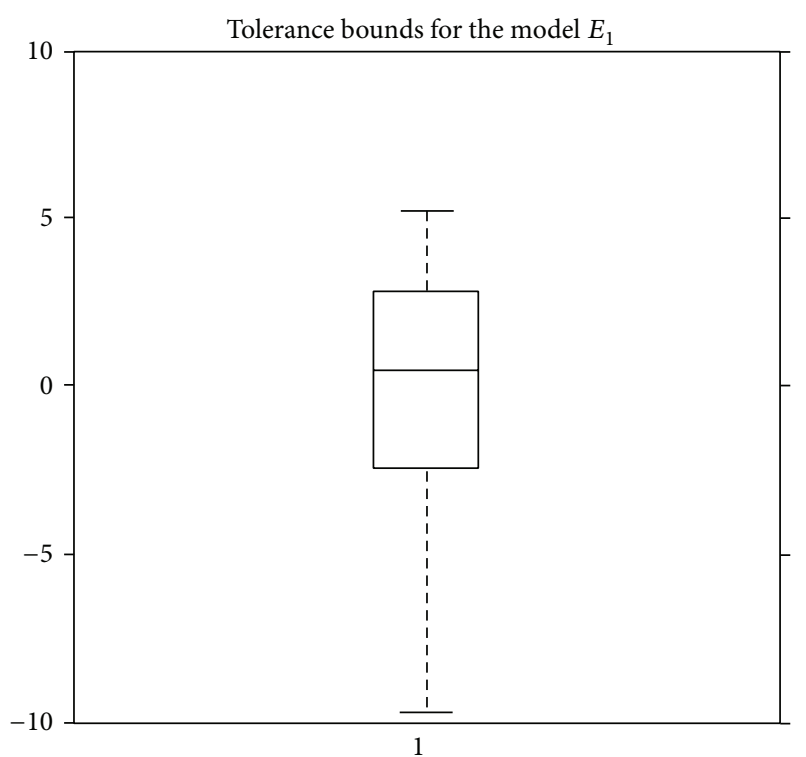

(b)

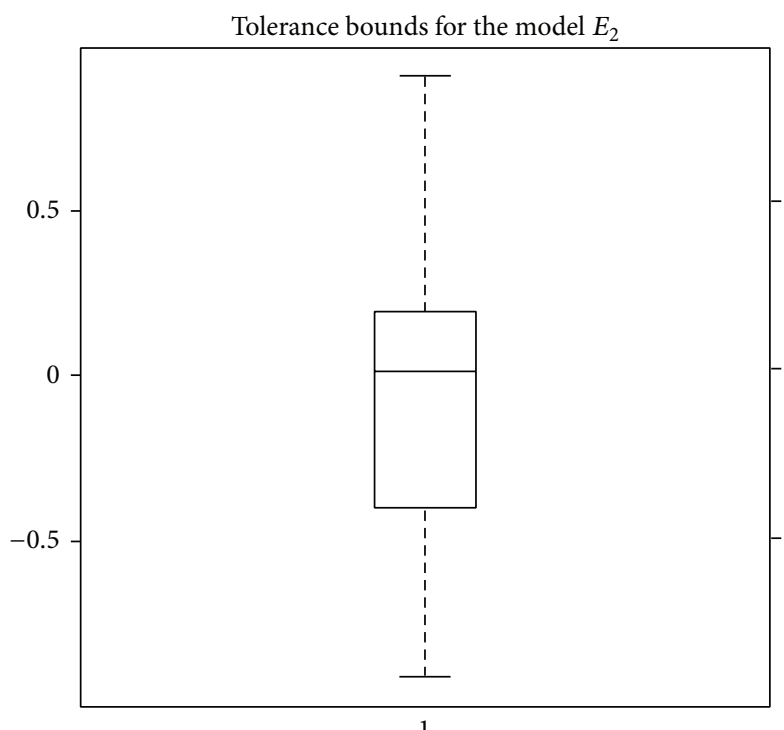

(c)

FIGURE 8: Tolerance bounds for best models proposed, $E_{0}, E_{1}$, and $E_{2}$.

the observations between paired observations, $d_{0}$ is the expected differences between means of the two samples, and $n$ is the number of pairs. Critical regions are constructed using the $t$-distribution with $n-1$ degrees of freedom.

The null hypothesis for this model is that the means of both samples are equal; therefore, $d_{0}$ becomes zero (alternative hypothesis is the means are different). For a confidence interval of $95 \%$ the critical values from $t$-distribution are $-2.056<t>2.056$, and for a confidence interval of $99 \%$ critical values are $-2.779<t>2.779$. Table 6 shows the computed test statistic $(t)$ for each model.

It can be observed from data in Table 6 that the test statistic lies between critical values for both confidence intervals; therefore the null hypothesis cannot be rejected and it can be assumed that the mean of the predicted values when compared with real data is equivalent; therefore, the models are reliable for these two confidence intervals.

\section{Conclusions}

The measurements of the UPV showed the most uniform data when compared against other NDTs; the samples of the second stage indicate velocities of pulse in different ranges; for samples of $\mathrm{w} / \mathrm{c}$ ratio $=0.50$ the velocity is within a range from 3.6 to $3.9 \mathrm{~km} / \mathrm{s}$, while for samples of $\mathrm{w} / \mathrm{c}$ ratio $=0.65$ the velocity is within the range of 3.3 to $3.6 \mathrm{~km} / \mathrm{s}$. 
TABLE 6: Computed test statistic $(t)$ for each of the prediction models.

\begin{tabular}{|c|c|c|c|c|c|}
\hline \multirow{2}{*}{ Model } & \multirow{2}{*}{$n$} & \multirow{2}{*}{ Test statistic $(t)$} & \multicolumn{2}{|c|}{ Critical values for different confidence intervals } & \multirow{2}{*}{ Statistical conclusion } \\
\hline & & & $95 \%$ & $99 \%$ & \\
\hline$E_{0}$ & 27 & 0.293 & & & \\
\hline$E_{1}$ & 27 & 0.229 & $-2.056<t>2.056$ & $-2.779<t>2.779$ & The null hypothesis cannot be rejected \\
\hline$E_{2}$ & 35 & -0.022 & & & \\
\hline
\end{tabular}

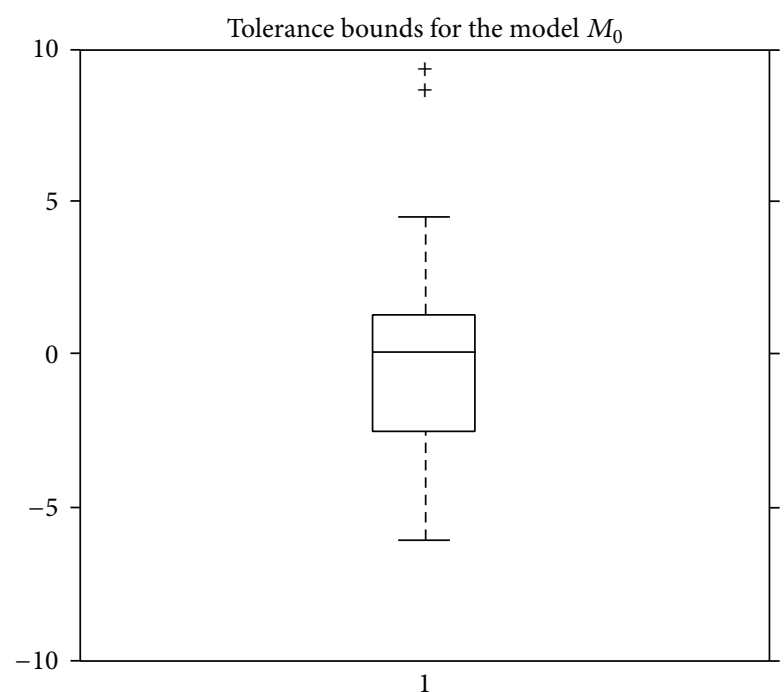

Figure 9: Tolerance bounds of the $M_{0}$ model, model proposed by other authors.

The resonant frequency is the NDT more affected by the morphology or geometry of the analyzed samples. Therefore, the resonance frequency should be used only if prismatic samples that comply with the dimensions indicated in the literature are tested [31]. Otherwise it will be difficult to obtain accurate frequency values; furthermore, this test cannot be applied in the field.

The rebound method should be used to determine the homogeneity of the concrete but not its $f^{\prime} c$ unless a correlation between the rebound number and $f^{\prime} c$ has been made.

The prediction models obtained are $E_{0}$ and $E_{1}$ with a correlation factor of 0.895 and 0.889 , respectively, to predict the $f^{\prime} c$ and the model $E_{2}$ with a correlation factor of 0.913 to predict the MOR. These models are linear and provide better results than models formed by higher degree polynomials and also provide improved estimations than previous models proposed in the literature.

Nondestructive tests have a fairly wide scope, both in engineering and in other areas of knowledge; therefore it is recommended to continue with investigations using nondestructive techniques for better documentation and reliability thereof.

With the proposed models, it is possible to take readings of nondestructive testing and predicting $f^{\prime} c$ or MOR of the structure in the field and samples are not necessary for that purpose.

\author{
Abbreviations \\ Resistive: Electrical resistivity \\ Freq: Resonant frequencies \\ Rebound: Rebound number \\ freq_long: Resonance frequency in the longitudinal mode \\ freq_trans: Resonance frequency in the transverse mode \\ MOR: $\quad$ Modulus of rupture \\ $f^{\prime} c$ : Compressive strength \\ LOOCV: Leave-one-out cross-validation.
}

\section{Conflict of Interests}

The authors declare that there is no conflict of interests regarding the publication of this paper.

\section{References}

[1] ASTMC39 / C39M-03, "Standard test method for compressive strength of cylindrical concrete specimens," in Annual Book of ASTM Standards, ASTM, West Conshohocken, Pa, USA, 2003.

[2] ASTM C 78-10, "Standard test method for flexural strength of concrete (using simple beam with third-point loading)," in Annual Book of ASTM Standards, vol. 04.02, ASTM, West Conshohocken, Pa, USA, 2002.

[3] C. Kohl, M. Krause, C. Maierhofer, and J. Wostmann, "2D- And 3D-visualisation of NDT-data using data fusion technique," Materials and Structures/Materiaux et Constructions, vol. 38, no. 283, pp. 817-826, 2005.

[4] ACI 318, Requisitos de Reglamento para Concreto Estructural (ACI 318S-05) y Comentario (ACI 318SR-05), American Concrete Institute, 2005.

[5] ASTM C 469-02, "Standard test method for static modulus of elasticity and poisson's ratio of concrete in compression," in Annual Book of ASTM Standards, vol. 04.02, ASTM, West Conshohocken, Pa, USA, 2002.

[6] L. Kwang-Myong, K. Dong-Soo, and K. Jee-Sang, "Determination of dynamic Young's modulus of concrete at early ages by impact resonance test," Journal of Civil Engineering, vol. 1, no. 1, pp. 11-18, 1997.

[7] R. Beutel, H.-W. Reinhardt, C. U. Grosse et al., "Quantitativer Verfahrensvergleich," in Bergmeister, pp. 567-573, Ernst \& Sohn, 2007.

[8] American Concrete Institute and S. P. Pessiki, American Concrete Institute, Farmington Hills, Mich, USA, 2003.

[9] Q. Huang, P. Gardoni, and S. Hurlebaus, "Predicting concrete compressive strength using ultrasonic pulse velocity and rebound number," ACI Materials Journal, vol. 108, no. 4, pp. 403-412, 2011. 
[10] IAEA, Guidebook on Non-Destructive Testing of Concrete Structures, International Atomic Energy Agency, Vienna, Austria, 2002.

[11] A. Samarin and P. Meynink, "Use of combined ultrasonic and rebound hammer method for determining strength of concrete structural members," Concrete International, vol. 3, no. 3, pp. 25-29, 1981.

[12] R. Miretti, M. F. Carrasco, R. O. Grether, and C. R. Passerino, "Combined non-destructive methods applied to normal-weight and lightweight-concrete," Insight, vol. 46, no. 12, pp. 748-753, 2004.

[13] J. Hoła and K. Schabowicz, "New technique of nondestructive assessment of concrete strength using artificial intelligence," NDT \& E International, vol. 38, no. 4, pp. 251-259, 2005.

[14] M. A. Ploix, V. Garnier, D. Breysse, and J. Moysan, "NDT data fusion for evaluating concrete structures," in Proceedings of the 37th Annual Review of Progress in Quantitative Nondestructive Evaluation (QNDE '10), pp. 1307-1314, San Diego, Calif, USA, July 2011.

[15] V. Kaftandjian, Y. M. Zhu, O. Dupuis, and D. Babot, “The combined use of the evidence theory and fuzzy logic for improving multimodal nondestructive testing systems," IEEE Transactions on Instrumentation and Measurement, vol. 54, no. 5, pp. 19681977, 2005.

[16] C. Maierhofer, G. Zacher, C. Kohl, and J. Wöstmann, "Evaluation of radar and complementary echo methods for NDT of concrete elements," Journal of Nondestructive Evaluation, vol. 27, no. 1-3, pp. 47-57, 2008.

[17] A. A. Shah and Y. Ribakov, "Non-destructive measurements of crack assessment and defect detection in concrete structures," Materials and Design, vol. 29, no. 1, pp. 61-69, 2008.

[18] Z. Liu, D. S. Forsyth, J. P. Komorowski, K. Hanasaki, and T. Kirubarajan, "Survey: state of the art in NDE data fusion techniques," IEEE Transactions on Instrumentation and Measurement, vol. 56, no. 6, pp. 2435-2451, 2007.

[19] A. P. Aizebeokhai, "2D and 3D geoelectrical resistivity imaging: theory and field design," Scientific Research and Essays, vol. 5, no. 23, pp. 3592-3605, 2010.

[20] S. H. Ward, "Electrical, electromagnetic, and magnetotelluric methods: geophysics," Geophysics, vol. 45, pp. 1659-1666, 1980.

[21] T. Acosta Andrés Antonio, M. Molina Wilfrido, L. González María Guadalupe, and P. Gallardo Alejandro, "Cactus based admixture as corrosion inhibitor for steel rebars of reinforced concrete," Tech. Rep. 328, 2010.

[22] F. Chen, J.-G. Xiu, J.-Z. An, C.-T. Liao, and D.-Y. Chen, "Detecting rupture precursors and determining the main fracture spread direction of rock with dynamic rock resistivity change anisotropy," Acta Seismologica Sinica English Edition, vol. 13, no. 2, pp. 234-237, 2000.

[23] S. Y. Liu, Y. J. Du, L. H. Han, and M. F. Gu, "Experimental study on the electrical resistivity of soil-cement admixtures," Environmental Geology, vol. 54, no. 6, pp. 1227-1233, 2008.

[24] J. Cao and D. D. L. Chung, "Defect dynamics of cement mortar under repeated loading, studied by electrical resistivity measurement," Cement and Concrete Research, vol. 32, no. 3, pp. 379-385, 2002.

[25] J. F. Lataste, C. Sirieix, D. Breysse, and M. Frappa, "Electrical resistivity measurement applied to cracking assessment on reinforced concrete structures in civil engineering," Non Destructive Testing and Engineering International, vol. 36, no. 6, pp. 383-394, 2003.
[26] O. Sengul, "Factors affecting the electrical resistivity of concrete," in Nondestructive Testing of Materials and Structures, vol. 6 of RILEM Bookseries, pp. 263-269, Springer, 2013.

[27] J. W. Lencioni and M. D. de Lima, "A study of the parameters that affect the measurements of superficial electrical resistivity of concrete," Nondestructive Testing of Materials and Structures, vol. 6, pp. 271-276, 2013.

[28] V. M. Malhotra and N. J. Carino, Handbook on Nondestructive Testing of Concrete, CRC Press, Boca Raton, Fla, USA, 2004.

[29] R. Jones and I. Facaoaru, "Recommendations for testing concrete by the ultrasonic pulse method," Matériaux et Constructions, vol. 2, no. 4, pp. 275-284, 1969.

[30] ACI Committee 228, "In-place methods for determination of strength of concrete," Manual of Concrete Practice AC1228.1R, American Concrete Institute, Detroit, Mich, USA, 1989.

[31] R. Jones, Non-Destructive Testing of Concrete, Cambridge University Press, London, UK, 1962.

[32] T. T. Wu and T. F. Lin, "The stress effect on the ultrasonic velocity variations of concrete under repeated loading," ACI Materials Journal, vol. 95, no. 5, pp. 519-524, 1998.

[33] S. F. Selleck, E. N. Landis, M. L. Peterson, S. P. Shah, and J. D. Achenbach, "Ultrasonic investigation of concrete with distributed damage," ACI Materials Journal, vol. 95, no. 1, pp. 27-36, 1998.

[34] ACI Committee 228, Nondestructive Test Methods for Evaluation of Concrete in Structures, 1998.

[35] J. L. Rose, Ultrasonic Waves in Solid Media, 1999.

[36] V. R. Sturrup, F. J. Vecchio, and H. Caratin, Pulse Velocity as a Measure of Concrete Compressive Strengths, 1984.

[37] D. A. Anderson and R. K. Seals, "Pulse velocity as a predictor of 28 and 90 days strength," Journal of the American Concrete Institute, vol. 78, no. 2, pp. 116-119, 1981.

[38] M. F. Kaplan, "Compressive strength and ultrasonic pulse velocity relationships for concrete in columns," ACI Journal, vol. 29, no. 54-37, p. 675, 1958.

[39] M. F. Kaplan, "The effects of age and water to cement ratio upon the relation between ultrasonic pulse velocity and compressive strength of concrete," Magazine of Concrete Research, vol. 11, no. 32, pp. 85-92, 1959.

[40] H. Irie, Y. Yoshida, Y. Sakurada, and T. Ito, "Non-destructivetesting methods for concrete structures," NTT Technical Review, vol. 6, no. 5, pp. 1-8, 2008.

[41] F. B. Hornibrook, "Application of sonic method to freezing and thawing studies of concrete," ASTM Bulletin, no. 101, p. 5, 1939.

[42] W. T. Thomson, "Measuring changes in physical properties of concrete by the dynamic method," Proceedings of ASTM, vol. 40, p. 1113, 1940.

[43] L. Obert and W. I. Duvall, "Discussion of dynamic methods of testing concrete with suggestions for standardization," ASTM Proceedings, vol. 41, p. 1053, 1941.

[44] ASTM C 215-02, "Standard test method for fundamental transverse, longitudinal, and torsional resonant frequencies of concrete specimens," in Annual Book of ASTM Standards, vol. 04.02, ASTM, West Conshohocken, Pa, USA, 2003.

[45] V. M. Malhotra, Testing of Hardened Concrete: Nondestructive Methods, ACI Monograph no. 9, American Concrete Institute, Detroit, Mich, USA, 1976.

[46] N. Swamy and G. Rigby, "Dynamic properties of hardened paste, mortar and concrete," Matériaux et Constructions, vol. 4, no. 1, pp. 13-40, 1971. 
[47] K. H. Hsieh, M. W. Halling, and P. J. Barr, "Overview of vibrational structural health monitoring with representative case studies," Journal of Bridge Engineering, vol. 11, no. 6, pp. 707-715, 2006.

[48] A. Bagchi, J. Humar, H. Xu, and A. S. Noman, "Model-based damage identification in a continuous bridge using vibration data," Journal of Performance of Constructed Facilities, vol. 24, no. 2, pp. 148-158, 2010.

[49] CSN EN 12504-2, "Testing concrete in structures-part 2: nondestructive testing-determination of rebound number," Czech Standards Institute, Prague, Czech Republic, 2002.

[50] “Testing of concrete by hardness testing method," Tech. Rep. CSN 731373, Czech Standards Institute, Prague, Czech Republic, 1983.

[51] ASTM C 805/C805M-08, Standard Test Method for Rebound Number of Hardened Concrete, ASTM International, West Conshohocken, Pa, USA, 2008.

[52] JGJ/T 23-2001-J 155-2001, Technical Specification for Inspection of Concrete Compressive Strength by Rebound Method, 2001, (Chinese).

[53] K. Ramyar and P. Kol, "Destructive and non-destructive test methods for estimating the strength of concrete," Cement and Concrete World, vol. 2, pp. 46-54, 1996.

[54] U. Bellander, Testing Methods for Estimating Compressive Strength in Finished Structures-Evaluation of Accuracy and Testing System, 1979.

[55] B. Hobbs and M. T. Kebir, "Non-destructive testing techniques for the forensic engineering investigation of reinforced concrete buildings," Forensic Science International, vol. 167, no. 2-3, pp. 167-172, 2007.

[56] J. G. Wiebenga, A Comparison between Various Combined Non-Destructive Testing Methods to Derive the Compressive Strength of Concrete, Instituut TNO voor Bouwmaterialen en Bouwconstructies, 1968.

[57] E. Arioglu, O. Odbay, H. Alper, and B. Arioglu, "A new formula and application results for prediction of concrete compressive strength by combined non-destructive method," Concrete Prefabrication, vol. 28, pp. 5-11, 1994.

[58] R. Sriravindrajah, Y. H. Loo, and C. T. Tam, "Strength evaluation of recycled-aggregate concrete by in-situ tests," Materials and Structures, vol. 21, no. 4, pp. 289-295, 1988.

[59] E. Arioglu and O. Köylüoglu, "Prediction of concrete strength by destructive and nondestructive methods," Cement and Concrete World, vol. 3, pp. 33-34, 1996.

[60] G. F. Kheder, "Two stage procedure for assessment of in situ concrete strength using combined non-destructive testing," Materials and Structures, vol. 32, no. 220, pp. 410-417, 1999.

[61] E. Arioglu and O. Manzak, Application of "SonReb" Method to Concrete Samples Produced in Yedpa Construction Site, 1991.

[62] B. Postacioglu, "New significations of the rebound hammer tests and the ultrasonic pulse velocity," Materials and Structures, vol. 18, no. 6, pp. 447-451, 1985.

[63] J.-K. Kim, C.-Y. Kim, S.-T. Yi, and Y. Lee, "Effect of carbonation on the rebound number and compressive strength of concrete," Cement and Concrete Composites, vol. 31, no. 2, pp. 139-144, 2009.

[64] K. L. Rens, T. J. Wipf, and F. W. Klaiber, "Review of nondestructive evaluation techniques of civil infrastructure," Journal of Performance of Constructed Facilities, vol. 11, no. 4, pp. 152160, 1997.
[65] ASTM C 143/C 143M-03, "Standard test method for slump of hydraulic-cement concrete," in Annual Book of ASTM Standards, vol. 04.02, ASTM, West Conshohocken, Pa, USA, 2003.

[66] S. C. Millard, J. A. Harrison, and A. J. Edwards, "Measurements of electrical resistivity of reinforced concrete structures for the assesment of corrosion risk," British Journal of NDT, vol. 31, pp. 617-621, 1989.

[67] R. Durar, Manual de Inspección, Evaluación y Diagnóstico de Corrosión en Estructuras de Hormigón Armado, CYTED, Programa Iberoamericano de Ciencia y Tecnología para el Desarrollo, 1998.

[68] Mexican-Standard-NMX-C-414-ONNCCE-2004, Building Industry, Hydraulic Cement, Specifications and Test Methods, 2004.

[69] ASTM C 150-04, "Standard Specification for Portland Cement," in Annual Book of ASTM Standards, ASTM, West Conshohocken, Pa, USA, 2004.

[70] E. Alpaydin, Introduction to Machine Learning, 2009.

[71] Y. Tanigawa, K. Baba, and H. Mori, "Estimation of concrete strength by combined non-destructive testing method," September 1984.

[72] C. Elkan, Evaluating Classifiers, 2012.

[73] R. E. Walpole, R. H. Myers, S. L. Myers, and K. Ye, Probability \& Statistics for Engineers \& Scientists, edited by D. Lynch, Prentice Hall, Boston, Mass, USA, 9th edition, 2012. 

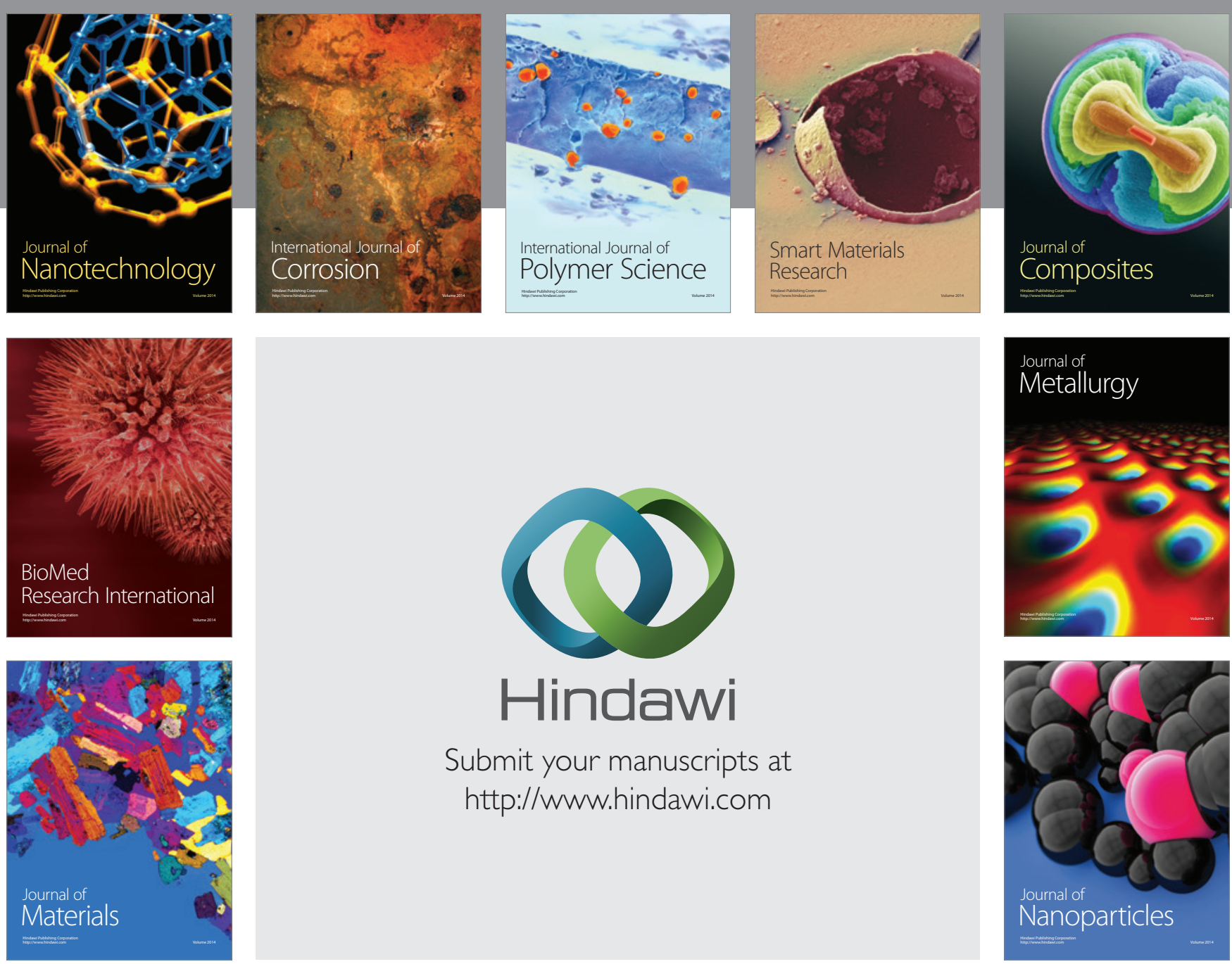

Submit your manuscripts at http://www.hindawi.com
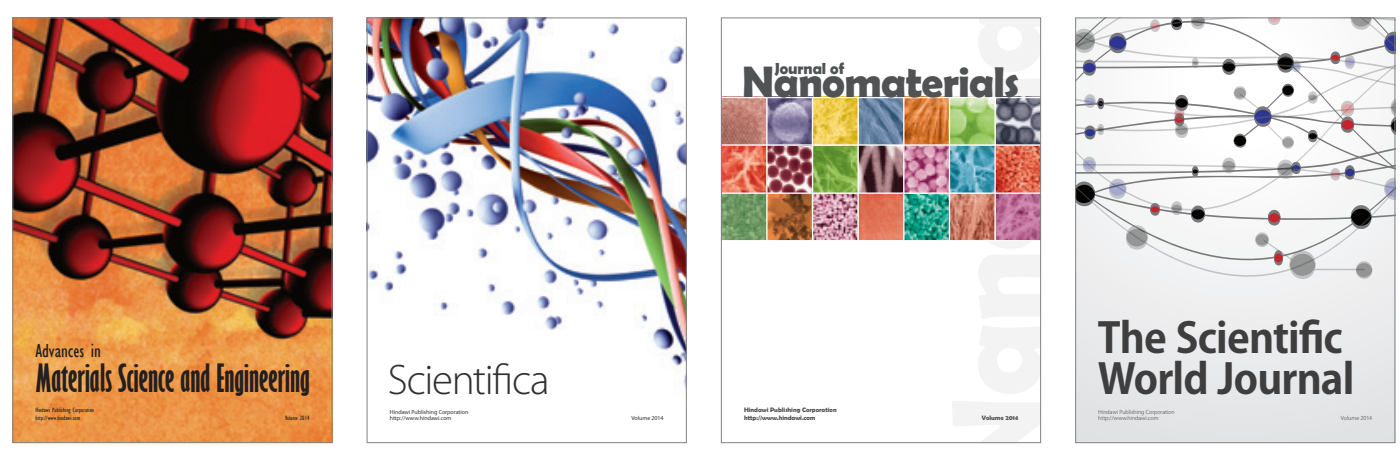

\section{The Scientific World Journal}
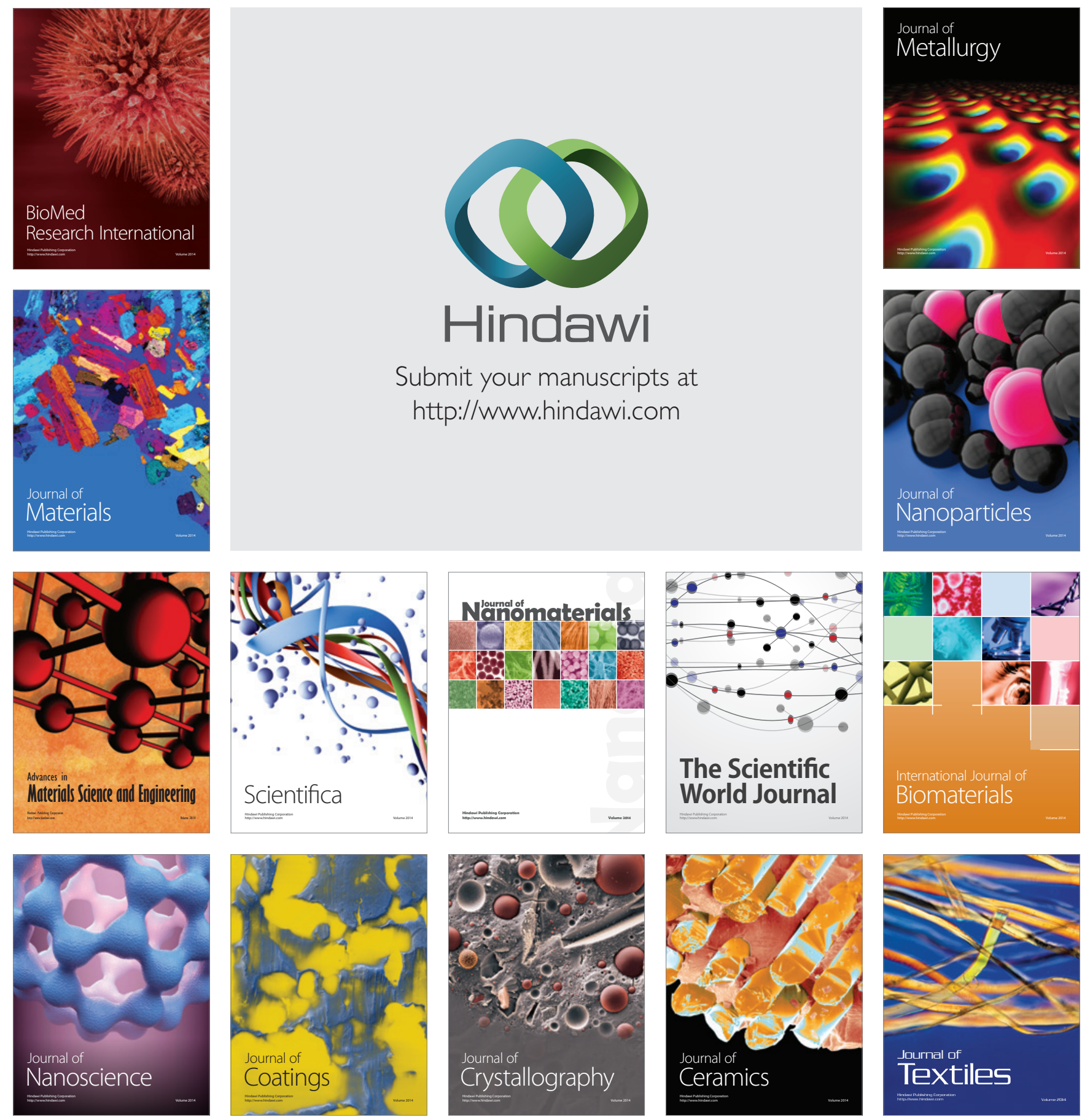